\title{
Properties of humic acids depending on the land use in different parts of Slovakia
}

\author{
Magdalena Banach-Szott ${ }^{1}$ (D) $\cdot$ Bozena Debska $^{1}$ (D) Erika Tobiasova $^{2}$
}

Received: 25 March 2021 / Accepted: 25 May 2021 / Published online: 8 June 2021

(C) The Author(s) 2021

\begin{abstract}
Many studies report organic carbon stabilization by clay minerals, but the effects of land use and soil type on the properties of humic acids (HAs) are missing. The aim of the paper is to determine the effects of land use and soil types on the characteristics of HAs, which have a considerable influence on organic matter quality. It was hypothesised that the effect of the land use on HAs properties depends on the particular size distribution. The research was performed in three ecosystems: agricultural, forest, and meadow, located in Slovakia. From each of them, the samples of 4 soil types were taken: Chernozem, Luvisol, Planosol, and Cambisol. The soil samples were assayed for the content of total organic carbon (TOC) and the particle size distribution. HAs were extracted with the Schnitzer method and analysed for the elemental composition, spectrometric parameters in the UV-VIS range, and hydrophilic and hydrophobic properties, and the infrared spectra were produced. The research results have shown that the properties of HAs can be modified by the land use and the scope and that the direction of changes depends on the soil type. The HAs of Chernozem and Luvisol in the agri-ecosystem were identified with a higher "degree of maturity", as reflected by atomic ratios $(\mathrm{H} / \mathrm{C}, \mathrm{O} / \mathrm{C}, \mathrm{O} / \mathrm{H})$, absorbance coefficients, and the FT-IR spectra, as compared with the HAs of the meadow and forest ecosystem. However, as for the HAs of Cambisol, a higher "degree of maturity" was demonstrated for the meadow ecosystem, as compared with the HAs of the agri- and forest ecosystem. The present research has clearly identified that the content of clay is the factor determining the HAs properties. Soils with a higher content of the clay fraction contain HAs with a higher "degree of maturity".
\end{abstract}

Keywords Soils $\cdot$ Elemental composition $\cdot$ UV-VIS $\cdot$ HPLC

\section{Introduction}

The role of organic matter $(\mathrm{OM})$, including humic substances (HS), in the soil formation and development is

Responsible Editor: Kitae Baek

Magdalena Banach-Szott

mbanach@utp.edu.pl

Bozena Debska

debska@utp.edu.pl

Erika Tobiasova

erika.tobiasova@uniag.sk

1 Department of Biogeochemistry and Soil Science, University of Science and Technology, 6 Bernardynska St,

85-029 Bydgoszcz, Poland

2 Department of Soil Science, Slovak University of Agriculture in Nitra, 2 Tr. A. Hlinku St, 94976 Nitra, Slovakia unquestionable. OM is also an important indicator of soil fertility, and it plays an essential role in the efficiency of agriculture, the quality of the environment and global climate changes (Zech et al. 1997; Lal 2004; Schmidt et al. 2011; Tan 2014).

The content and properties of organic matter are conditioned by the physicochemical properties of the parent rock and climate conditions. However, the land use change is the most dynamic factor of soil organic matter (SOC) changes (Guo and Gifford 2002; Poeplau et al. 2011; Jonczak 2013; Viscarra-Rossel et al. 2014; Kukuls et al. 2019; Kunlanit et al. 2019). In the temperate climate zone, the capacity of soil for SOC storage increases in the following order: cropland $<$ forest $<$ grassland (Meersmans et al. 2008; Martin et al. 2011). Leifeld et al. (2005) and Lettens et al. (2005) claim that the forest SOC stocks can be higher than grassland stocks, and a change in use from forest to farmland results in significant declines in SOC stocks (Guo and Gifford 2002; Murty et al. 2002; Wei et al. 2014; Kunlanit et al. 2019). Wei et al. (2014) report on the largest decrease in the SOC stock in topsoil (0- 
$30 \mathrm{~cm}$ ) in temperate regions - 52\% followed by tropical regions $-41 \%$ and boreal regions $-31 \%$ (the values are the average decrease in the SOC stock for 3 periods $-\leq 10,11-$ $50,>50$ years which lapsed since the woodland was transformed into arable land).

One of the key SOC-stabilizing mechanisms is the soil interaction with mineral particles (Sollins et al. 1996; Von Lutzow et al. 2006). Due to a strong correlation between the SOC stocks and the content of clay presented in numerous research reports, the soil texture can be a promising factor applied as the SOC storage indicator (Hassink et al. 1997; Kaiser and Guggenberger 2000; Arrouays et al. 2006; Zinn et al. 2007).

As already mentioned, one of the most important organic carbon (OC) reservoirs is the soils of grasslands and forest soils. For that reason, the meadow and forest ecosystems are a land use preventing OC losses in soils. The OC losses triggered by soil processes are gas emissions of $\mathrm{CO}_{2}$ and $\mathrm{CH}_{4}$ as well as soluble organic carbon leaching to the groundwaters. It has been demonstrated that meadow ecosystems help limiting the OC losses from soil, and they are essential for the sustainable management of that element in the environment (Minami et al. 1993; Conant et al. 2001; Mannetje 2002; Lal 2011; Kampf et al. 2016).

Many reports point to progressive decreases in HS concentrations in soils converted from forest to arable land (Spaccini et al. 2006; Gonzalez-Perez et al. 2007; Guimaraes et al. 2013; Barancikova et al. 2016; Kunlanit et al. 2019), and as claimed by Feller and Beare (1997), Watanabe et al. (2001), and Jonczak (2013), the changes in land use can alter the chemical properties of soil HS. HS (fulvic acids, HAs, and humins) are the main fractions of SOM making its specific contribution to soil fertility. HS constitute a considerable part of the resources of OC and nitrogen (N) (Lal 1994; Milori et al. 2002; Zhang et al. 2019). Those compounds take part in all the processes which occur in soil and which affect its physical, chemical, and biological properties. HS improve the soil buffering capacity, supply the plants with available micronutrients, and immobilize organic contaminants and metals (McCarthy 2001; Yamashita et al. 2008; Canellas et al. 2010; Lanyi 2010). HS also determine the soil production potential, and by participating in the global carbon cycling, they play environmental functions (Hayes and Clapp 2001; Piccolo 2001; Lal 2006). For that reason, it is important to understand the nature, composition, and the dynamics of HS.

The molecules of HAs, with a humification progress, show a growing stability, e.g., in terms of elemental composition and spectroscopic properties (Dergacheva et al. 2012; Zhang et al. 2019). For that reason, one of the basic indicators applied to evaluate the properties of HAs is the elemental composition and, determined with it, values of the $\mathrm{H} / \mathrm{C}, \mathrm{O} / \mathrm{C}$, and $\mathrm{N} / \mathrm{C}$ atomic ratios. The numerical values of atomic ratios facilitate an approximation of the structure of the molecules of humic acids by evaluating the degree of condensation of aromatic rings $(\mathrm{H} / \mathrm{C}$ ratio) and the degree of maturity $(\mathrm{O} / \mathrm{C}, \mathrm{O} / \mathrm{H}, \mathrm{N} / \mathrm{C}$ ratios) (Rice and MacCarthy 1991; Fuentes et al. 2007; Canellas et al. 2010; Trubetskaya et al. 2013; Boguta et al. 2016).

An important criterion characterizing the HAs in terms of the molecular composition and their origin is the values of absorbance of their solutions in the UV-VIS range: $A_{280}$, $\mathrm{A}_{465}, \mathrm{~A}_{665}$, and the coefficients of absorbance $\mathrm{A}_{2 / 4}, \mathrm{~A}_{2 / 6}$, $\mathrm{A}_{4 / 6}$, and $\Delta \log \mathrm{K}$. Coefficients $\mathrm{A}_{2 / 4}, \mathrm{~A}_{2 / 6}, \mathrm{~A}_{4 / 6}$, and $\Delta \log \mathrm{K}$ are important indices of the degree of advancement of the humification of organic materials and the characteristics of the HS produced, as well as changes in the properties of the HAs which occur due to various anthropogenic factors (Kumada 1987; Chin et al. 1994; Tan 1998; Gonet and Debska 1999; Chen et al. 2002; Weishaar et al. 2003; Moran Vieyra et al. 2009; Polak et al. 2011; Rodriguez et al. 2016). For example, the research of the spectrometric parameters of the HAs of soils collected from primary forests, secondary forests, coffee plantations, and cultivated lands performed by Watanabe et al. (2001) suggests that the degree of HAs humification varied from site to site.

Infrared spectroscopy (FTIR) has also been a technique used for the structural characterization of HS, especially for the identification of functional groups within the humus macromolecule (Tan 1998; Cocozza and Miano 2002; Pajaczkowska et al. 2003; Polak et al. 2011; Kukuls et al. 2019).

Some essential information on the transformation of HAs is also provided by the results of high-performance liquid chromatography. Woelki et al. (1997), Preuße et al. (2000), Banach-Szott and Debska (2006), Sierra et al. (2006), and Debska et al. (2010), using the chromatographic analysis, separated the hydrophilic (HIL) and hydrophobic fractions (HOB-1 and HOB-2). The ratios of those fractions affect the solubility of HAs and, as a result, their migration deep down the soil profile. According to Debska et al. (2007) and Debska and Gonet (2007), with an increase in the degree of humification, the share of the HIL fraction in the molecules of HAs increases and the share of HOB fractions decreases. As a result, the HAs molecules with a higher "degree of maturity" showed a higher value of the HIL/ $\Sigma$ HOB ratio.

The aim of the paper has been to present the land use and soil types effect on the characteristics of HAs determining the OM quality in the soil of various types. There are many results on the processes of OC stabilization by binding clay; however, some results on the changes in elemental composition and the other properties of HAs depending on the land use and soil types are missing. It was hypothesised that the effect of the land use on the properties of HAs will depend on the particle size distribution (soil types). The research has been performed in three ecosystems: agricultural, forest, and meadow, located in various parts of Slovakia. The properties of HAs have been 
determined from the assay of the elemental composition, spectroscopy in the UV-VIS, and IR ranges and the HIL-HOB properties applying the high-performance liquid chromatography.

\section{Materials and methods}

\section{Materials}

The experiment included 4 soil types: Chernozem (Ch), Luvisol (Lu), Planosol (Pl), and Cambisol (Ca) (IUSS Working Group WRB 2014), each in three types of ecosystems: agri-ecosystem (AE), forest (FE), and meadow ecosystem (ME).

The areas are located in different parts of Slovakia (Fig. 1). Chernozem (Ch) comes from the location of Voderady $\left(48^{\circ} 16^{\prime} \mathrm{N}, 17^{\circ} 34^{\prime} \mathrm{E}\right)$, found on the northern border of the Danube Basin. The geological structure shows the Neogene strata, which consist mainly of claystones, sandstones, and andesites, covered with younger quaternary rocks represented by different fluvial and Aeolian sediments (Sajgalik et al. 1986). It is located in a warm climate region with an average annual temperature of $9.6^{\circ} \mathrm{C}$ and the total annual precipitation of $560 \mathrm{~mm}$ (Korec et al. 1997).

Planosol (Pl) comes from the location of Vavrecka $\left(49^{\circ} 38^{\prime}\right.$ $\mathrm{N}, 19^{\circ} 47^{\prime} \mathrm{E}$ ), found in Horna Orava, which is part of the Flysch Belt. The geological structure shows the alternation of clay slates, sandstones, and conglomerates in the layers of various depth. It is located in a cold climate region with an average annual temperature of $4.6^{\circ} \mathrm{C}$ and the total annual precipitation of $1010 \mathrm{~mm}$ (Sajgalik et al. 1986).

Cambisol ( $\mathrm{Ca}$ ) comes from the location of Prietrz $\left(48^{\circ} 40^{\prime}\right.$ $\mathrm{N}, 17^{\circ} 26^{\prime} \mathrm{E}$ ), on the Myjava Hills. The geological structure includes the Carpathian flysch, which consists mainly of marine deposits of claystones, shales, and sandstones (Sajgalik et al. 1986). It is located in a temperate climate region with an average annual temperature of $8.0^{\circ} \mathrm{C}$ and the total annual precipitation of $681 \mathrm{~mm}$ (Korec et al. 1997).
Luvisol ( $L u$ ) comes from the location of Plave Vozokany $\left(48^{\circ} 06^{\prime} \mathrm{N}, 18^{\circ} 46^{\prime} \mathrm{E}\right)$, in the northeast of the Danubian Upland. The geological structure involves clay, gravels, and sands covered with quaternary sediments (Sajgalik et al. 1986). It is located in a warm climate region with an average annual temperature of $10.4{ }^{\circ} \mathrm{C}$ and the total annual precipitation of $589 \mathrm{~mm}$ (Korec et al. 1997).

The agri-ecosystem included four crop rotations for each soil and land use (Table 1). The fields in the agri-ecosystems were located on different farms under real production conditions. The forest ecosystems were natural forests with human control, in all the cases they were hundreds of years of age. The dominant species in the stands were on Chernozem Quercus, on Luvisol - Alnus, on Planosol - Picea, and on Cambisol - Fagus, Quercus, and Carpinus. The meadow ecosystems were created by man at least 30 years ago.

\section{Methods}

The soil samples were collected with the Egner stick in three replications down to the depth of $0.30 \mathrm{~m}$ in the forest and meadow ecosystems. In the agri-ecosystems, collections were made in different fields with different crop rotations and different applications of farmyard manure (in 12 replications, the depth of $0.30 \mathrm{~m}$ ). The distance between the replications was $20 \mathrm{~m}$ in equilateral triangle. The distance between fields differed, depending on the locations; however, it was not more than $2 \mathrm{~km}$. The distance between the locations (Fig. 1) was not more than $200 \mathrm{~km}$. The sample replications for chemical analyses were combined and carefully mixed, dried in room temperature, and sieved $(2 \mathrm{~mm})$.

\section{Basic parameters of soils}

The particle size distribution was determined after dissolving $\mathrm{CaCO}_{3}$ with $2 \mathrm{M} \mathrm{HCl}$ and the oxidation of OM-with $30 \%$ $\mathrm{H}_{2} \mathrm{O}_{2}$. Silt, sand, and clay fractions were assayed applying the pipette method (Van Reeuwijk 2002). In the soil samples, the TOC was assayed applying wet combustion (Orlov and

Fig. 1 Soil sampling locations: 1 - Voderady, 2 - Vavrecka, 3 Prietrz, 4 - Plave Vozokany

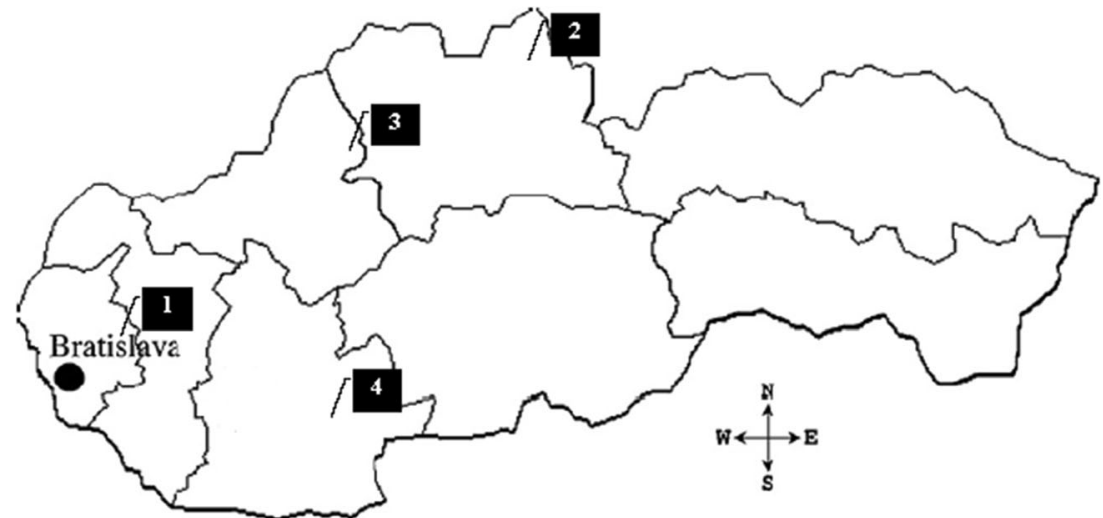


Table 1 The crop rotations for soils

\begin{tabular}{|c|c|c|c|}
\hline Soils & Vegetation & Soils & Vegetation \\
\hline Chernozem & $\begin{array}{l}\text { Helianthus annuus } \\
\text { Triticum aestivum } \mathrm{L} . \\
\text { Zea mays } \\
\text { Hordeum vulgare } \\
\text { Triticum aestivum } \mathrm{L} \text {. } \\
\text { Helianthus annuus } \\
\text { Triticum aestivum } \mathrm{L} . \\
\text { Zea mays }\end{array}$ & Planosol & $\begin{array}{l}\text { Triticum aestivum } L . \\
\text { Zea mays } \\
\text { Brassica napus var. napus } \\
\text { Triticum aestivum } L . \\
\text { Zea mays } \\
\text { Zea mays } \\
\text { Hordeum vulgare } \\
\text { Zea mays }\end{array}$ \\
\hline Luvisol & $\begin{array}{l}\text { Medicago sativa } \\
\text { Helianthus annuus } \\
\text { Triticum aestivum } \mathrm{L} . \\
\text { Pisum sativum } \\
\text { Brassica napus var. napus } \\
\text { Triticum aestivum L. } \\
\text { Helianthus annuus } \\
\text { Triticum aestivum } \mathrm{L} .\end{array}$ & Cambisol & $\begin{array}{l}\text { Medicago sativa } \\
\text { Medicago sativa } \\
\text { Triticum aestivum L. } \\
\text { Brassica napus var. napus } \\
\text { Triticum aestivum L. } \\
\text { Zea mays } \\
\text { Helianthus annuus } \\
\text { Triticosecale }\end{array}$ \\
\hline
\end{tabular}

Grishina 1981). The soil $\mathrm{pH}$ was potentiometrically measured in a supernatant suspension of a 1:2.5 soil/liquid mixture, and the liquid was $1 \mathrm{M} \mathrm{KCl}\left(\mathrm{pH}_{\mathrm{KCl}}\right)$ (Van Reeuwijk 2002).

\section{Extraction of humic acids}

HAs were extracted and purified according to the following procedure (Debska et al. 2010):

- Decalcification (24 h) with $0.05 \mathrm{M} \mathrm{HCl}(1: 10 \mathrm{w} / \mathrm{v})$. After centrifugation the residue was rinsed with distilled water till neutral.

- The extraction $(24 \mathrm{~h})$ of the remaining solid with $0.5 \mathrm{M}$ $\mathrm{NaOH}(1: 10 \mathrm{w} / \mathrm{v})$, with occasional mixing, followed by centrifugation.

- The precipitation $(24 \mathrm{~h})$ of HAs from the resulting alkaline extract with $2 \mathrm{M} \mathrm{HCl}$ to $\mathrm{pH}=2$ and centrifugation.

- The purification of the resulting HAs; the HAs residue was treated with a mixture of $\mathrm{HCl} / \mathrm{HF}\left(950 \mathrm{~mL} \mathrm{H}_{2} \mathrm{O}, 5\right.$ $\mathrm{mL} \mathrm{HCl}, 5 \mathrm{~mL} \mathrm{HF}$ ) over a 24-h period, followed by centrifugation. This procedure was repeated three times. The HAs residue was treated with distilled water until a zero reaction to chloride was achieved.

The preparations were lyophilised and powdered in the agate mortar. The ash content in the HAs preparations was lower than $2 \%$.

\section{Characteristics of humic acids}

The HAs separated were analysed for:
- Elemental composition (Perkin Elmer, series II CHN analyser, Shelton, USA). The $\mathrm{H} / \mathrm{C}, \mathrm{O} / \mathrm{C}, \mathrm{O} / \mathrm{H}$, and $\mathrm{N} / \mathrm{C}$ atomic ratios and $\omega$ (internal oxidation degree) were calculated using the following formula: $\omega=(2 \mathrm{O}+3 \mathrm{~N}-\mathrm{H}): \mathrm{C}$

where $\mathrm{O}, \mathrm{N}, \mathrm{H}, \mathrm{C}$-content in atomic $\%$.

- UV-VIS absorption spectra (Perkin Elmer UV-VIS Spectrometer, Lambda 20, Ueberlingen, Germany). VIS spectra were obtained from $0.02 \%$ HAs solutions in $0.1 \mathrm{M} \mathrm{NaOH}$ and UV-spectra after fivefold dilution. The absorbance was measured at $280 \mathrm{~nm}\left(\mathrm{~A}_{280}\right)$, $400 \mathrm{~nm}\left(\mathrm{~A}_{400}\right), 465 \mathrm{~nm}\left(\mathrm{~A}_{465}\right), 600 \mathrm{~nm}\left(\mathrm{~A}_{600}\right)$, and $665 \mathrm{~nm}\left(\mathrm{~A}_{665}\right)$ and used to calculate the coefficient values:

- $\quad \mathrm{A}_{2 / 4}-280 \mathrm{~nm}$ and $465 \mathrm{~nm}$ absorbance ratio

- $\mathrm{A}_{2 / 6}-280 \mathrm{~nm}$ and $665 \mathrm{~nm}$ absorbance ratio

- $\mathrm{A}_{4 / 6}-465 \mathrm{~nm}$ and $665 \mathrm{~nm}$ absorbance ratio

- $\Delta \log \mathrm{K}=\log \mathrm{A}_{400}-\log \mathrm{A}_{600}$ (sKumada 1987);

- Infrared transmittance spectra (Perkin-Elmer FT-IR Spectrometer Spectrum BX, software Spectrum V2.00, Llantrisant, Great Britain) over $400-4400 \mathrm{~cm}^{-1}$ were recorded for HAs (3 mg) in $\mathrm{KBr}(800 \mathrm{mg})$. To increase the legibility of the spectra, deconvolution was applied, with a filter making the bands of $\gamma=4$ narrower and using the process of smoothing, for which the length parameter was $1=80 \%$ (Cocozza and Miano 2002).

- HIL and HOB properties were determined with liquid chromatograph HPLC Series 200 with a DAD by 
Perkin-Elmer, Shelton, USA. The separation involved the use of column X-Terra C18, $5 \mu \mathrm{m}, 250 \times 4.6 \mathrm{~mm}$. The solutions of HAs were applied in $0.01 \mathrm{M} \mathrm{NaOH}$ of the concentration of $2 \mathrm{mg} \mathrm{mL}^{-1}$; the injection of the sample was $10 \mu \mathrm{L}$; solvent - acetonitrile - water; solvents flow in the gradient (ratio $\mathrm{H}_{2} \mathrm{O}: \mathrm{ACN}(\mathrm{v} / \mathrm{v})$ over 0-6 $\mathrm{min}-99.5$ : $0.5,7-13 \mathrm{~min}-70: 30,13-20 \mathrm{~min}-10: 90)$; detection at the excitation/emission wavelength $(\lambda \mathrm{ex} / \lambda \mathrm{em})$ of $270 /$ $330 \mathrm{~nm}$. Based on the areas determined under peaks, the share of HIL and HOB $\left(\sum \mathrm{HOB}=\mathrm{HOB}-1+\mathrm{HOB}-2+\right.$ HOB-3) fractions in HAs molecules and parameter HIL/ $\sum$ HOB was determined (Woelki et al. 1997; Preuße et al. 2000; Debska et al. 2007).

\section{Statistical analysis}

The significance of differences of the parameters between land uses (agri-ecosystem (AE), forest (FE), and meadow ecosystems (ME)) within a soil type was evaluated with Duncan's post hoc test at $\mathrm{p}<0.05$.

The effect of the soil type and the land use on the properties of HAs was defined with cluster analysis. The method involves dividing the data set into groups to produce clusters in which the elements are similar to one another and, at the same time, different from the elements from the other groups. The groups of similar treatments are presented in a form of dendrogram. In a given group, the smaller the Euclidean distance, the more similar the objects. Data clustering was performed with the Ward method. The analysis was made after data standardization. The cluster analysis was performed based on the elemental composition $(\mathrm{C}, \mathrm{H}, \mathrm{N}, \mathrm{O}, \mathrm{H} / \mathrm{C}, \mathrm{O} / \mathrm{H}$, $\mathrm{O} / \mathrm{C}, \mathrm{N} / \mathrm{C}, \omega)$, spectrometric parameters $\left(\mathrm{A}_{280}, \mathrm{~A}_{465}, \mathrm{~A}_{665}\right.$, $\mathrm{A}_{2 / 4}, \mathrm{~A}_{2 / 6}, \mathrm{~A}_{4 / 6}$, and $\Delta \log \mathrm{K}$ ), as well as the HIL-HOB properties. The method involves dividing the data set into groups to produce clusters where the elements are similar to one another and, at the same time, different from the elements of the other groups. The relationships between the share of clay, silt, and sand fraction and the basic parameters of HAs were defined using the Pearson's correlation coefficients $(\mathrm{P} \leq 0.05)$. The above relationships were determined using statistics software STATISTICA MS 12.

\section{Results and discussion}

\section{Basic parameters of soils}

One of the key factors controlling the rate of the SOM circulation is field aggregates produced by combining clay particles with organic particles (mineral-organic particles). The soils differed significantly in terms of the particle size distribution (Table 2). The highest content of silt and clay fractions and the lowest of the sand fraction were recorded for Luvisol. Chernozem showed a similar content of sand and silt fractions (34.9 and 36.6\%, respectively). Cambisol demonstrated a similar content of sand and clay fraction (23.0, 24.5\%, respectively) and Planosol a similar content of silt and clay. The lowest content of TOC was reported for Cambisol and the highest for Planosol. The analysis of correlation did not show a significant dependence between the content of clay and the content of TOC; however, as reported in literature, one cannot exclude the effect of clay on the stability of SOM (Wiesmeier et al. 2019). As evident from the literature reports (Six et al. 2002; Wiesmeier et al. 2015), it is not just the quantity of the fine fraction but also its quality which drives SOC retention in soils. Liang et al. (2009) and Wiesmeier et al. (2015) show that the correlation between SOC and clay strongly depends on climate conditions, land use, and clay type. However, as reported in literature (Wiesmeier et al. 2019), despite a lack of significant correlations, one cannot exclude the effect of clay on SOM stability.

\section{Properties of humic acids}

According to De Moraes et al. (2011), the changes in land use practices can alter the chemical properties of soil HS. In this paper, the changes in land use practices are clearly reflected in the elemental composition (in atomic \%) of HAs (Table 3). The content of $\mathrm{C}$ in the molecules of HAs ranged from 33.38 to $39.55 \%, \mathrm{H}$ from 35.57 to $43.81 \%, \mathrm{~N}$ from 2.55 to $4.21 \%$, and $\mathrm{O}$ accounted for $18.10-22.80 \%$. The highest share of $\mathrm{C}$ was recorded for the molecules of the HAs of Luvisol sampled from the forest ecosystem. The lowest share of that element as well as $\mathrm{N}$ was found for the HAs of Planosol (FE). The lowest content of $\mathrm{H}$ and the highest content of $\mathrm{O}$ were recorded in the HAs of Chernozem from the agri-ecosystem (AE).

Table 3 also presents the values of the $\mathrm{C}, \mathrm{H}, \mathrm{O}$, and $\mathrm{N}$ atomic ratios. With the values of $\mathrm{H} / \mathrm{C}$ atomic ratio, one can determine the degree of condensation of aromatic rings and, as a result, the "degree of maturity" of the molecules of HAs. The values of the $\mathrm{H} / \mathrm{C}$ ratio for all the variants ranged from 0.91 to 1.31 (Table 3), which shows that the HAs analysed contained the aromatic systems coupled with the aliphatic chain containing up to 10 atoms of C (Van Krevelen 1950). The parameter used to describe the advancement of the process of humification is also the degree of internal oxidation $(\omega)$ of the HAs molecules and the $\mathrm{O} / \mathrm{C}, \mathrm{O} / \mathrm{H}$, and $\mathrm{N} / \mathrm{C}$ ratios. Higher $\omega, \mathrm{O} / \mathrm{C}$, and $\mathrm{O} / \mathrm{H}$ values and lower $\mathrm{H} / \mathrm{C}$ values correspond to the $\mathrm{HAs}$ with a higher "degree of maturity" (Sanchez-Monedero et al. 2002; Gonet et al. 2007).

Dergacheva et al. (2012) stress that the value of the H/C ratio depends on the conditions the HAs originated from. As seen from the data presented (Table 3), the direction of the changes in the elemental composition of HAs molecules was conditioned by the soil type. The lowest values of the $\mathrm{H} / \mathrm{C}$ and $\mathrm{N} / \mathrm{C}$ ratios as well as the highest values of the $\mathrm{O} / \mathrm{H}$ ratio and 
Table 2 Basic characteristics of soil samples (mean values and standard deviation)

\begin{tabular}{|c|c|c|c|c|c|c|}
\hline Soils & Ecosystems & Sand & $\begin{array}{l}\text { Silt } \\
(\%)\end{array}$ & Clay & $\begin{array}{l}\mathrm{pH} / \\
\mathrm{KCl}\end{array}$ & $\begin{array}{l}\text { TOC } \\
\left(\mathrm{g} \mathrm{kg}^{-1}\right)\end{array}$ \\
\hline \multirow[t]{3}{*}{$\mathrm{Ch}^{1}$} & $\mathrm{AE}$ & $29.8 \pm 2.0^{2}$ & $40.4 \pm 1.1$ & $29.8 \pm 2.0$ & 7.28 & $17.9 \pm 1.7$ \\
\hline & $\mathrm{FE}$ & $38.3 \pm 1.0$ & $33.0 \pm 1.9$ & $28.7 \pm 1.0$ & 7.52 & $29.6 \pm 1.1$ \\
\hline & $\mathrm{ME}$ & $36.7 \pm 0.9$ & $36.3 \pm 0.6$ & $27.0 \pm 1.1$ & 7.57 & $29.1 \pm 1.0$ \\
\hline Mean & & 34.9 & 36.6 & 28.5 & & 25.5 \\
\hline \multirow[t]{3}{*}{$\mathrm{Lu}$} & $\mathrm{AE}$ & $13.2 \pm 0.8$ & $58.0 \pm 0.8$ & $28.8 \pm 0.3$ & 5.85 & $14.8 \pm 1.9$ \\
\hline & $\mathrm{FE}$ & $19.1 \pm 0.9$ & $52.1 \pm 1.8$ & $28.8 \pm 2.3$ & 5.05 & $30.1 \pm 0.9$ \\
\hline & $\mathrm{ME}$ & $14.5 \pm 1.0$ & $51.5 \pm 1.1$ & $34.0 \pm 2.1$ & 6.56 & $18.9 \pm 0.6$ \\
\hline Mean & & 15.6 & 53.9 & 30.5 & & 21.3 \\
\hline \multirow[t]{3}{*}{ Pl } & $\mathrm{AE}$ & $63.9 \pm 0.7$ & $14.0 \pm 0.7$ & $22.1 \pm 0.3$ & 5.97 & $20.9 \pm 1.9$ \\
\hline & $\mathrm{FE}$ & $45.9 \pm 1.1$ & $37.8 \pm 0.3$ & $16.3 \pm 1.1$ & 5.01 & $36.9 \pm 0.3$ \\
\hline & $\mathrm{ME}$ & $60.4 \pm 0.8$ & $17.9 \pm 2.2$ & $21.7 \pm 1.4$ & 6.01 & $22.5 \pm 1.0$ \\
\hline Mean & & 56.7 & 23.2 & 20.0 & & 26.8 \\
\hline \multirow[t]{3}{*}{$\mathrm{Ca}$} & $\mathrm{AE}$ & $34.9 \pm 0.6$ & $44.3 \pm 1.0$ & $20.8 \pm 1.2$ & 7.08 & $13.0 \pm 1.0$ \\
\hline & $\mathrm{FE}$ & $17.0 \pm 1.0$ & $58.0 \pm 1.3$ & $25.0 \pm 1.0$ & 6.37 & $16.7 \pm 0.4$ \\
\hline & $\mathrm{ME}$ & $17.1 \pm 0.6$ & $55.1 \pm 0.9$ & $27.8 \pm 1.5$ & 5.93 & $11.6 \pm 0.7$ \\
\hline Mean & & 23.0 & 52.5 & 24.5 & & 13.8 \\
\hline
\end{tabular}

${ }^{1}$ Ch Chernozem, Lu Luvisol, Pl Planosol, Ca Cambisol, AE agricultural ecosystem, FE forest ecosystem, ME meadow ecosystem, TOC total organic carbon

${ }^{2}$ Standard deviation $(\mathrm{n}=3)$

the highest $\omega$ value were recorded for the molecules of the HAs of Chernozem in the agri-ecosystem, while the lowest values of the $\mathrm{O} / \mathrm{H}$ ratio and the highest of the $\mathrm{N} / \mathrm{C}$ ratio were found for the HAs of Chernozem of the forest ecosystem. The above dependencies point to the HAs of agri-ecosystem showing the highest and the HAs of the forest ecosystem - the lowest "degree of maturity" (Sanchez-Monedero et al. 2002; Gonet et al. 2007).

Table 3 Mean values of elemental composition with standard deviation and atomic ratio of humic acids

\begin{tabular}{|c|c|c|c|c|c|c|c|c|c|c|}
\hline Soils & Ecosystems & $\begin{array}{l}\mathrm{C} \\
{[\% \text { atomic }]}\end{array}$ & $\mathrm{H}$ & $\mathrm{N}$ & $\mathrm{O}$ & $\mathrm{H} / \mathrm{C}$ & $\mathrm{N} / \mathrm{C}$ & $\mathrm{O} / \mathrm{C}$ & $\mathrm{O} / \mathrm{H}$ & $\omega^{4}$ \\
\hline \multirow[t]{3}{*}{$\mathrm{Ch}^{1}$} & $\mathrm{AE}$ & $38.93 \pm 0.29^{3}$ & $35.57 \pm 0.38$ & $2.71 \pm 0.04$ & $22.80 \pm 0.18$ & $0.91 b^{2}$ & $0.070 \mathrm{c}$ & $0.586 \mathrm{a}$ & $0.641 \mathrm{a}$ & $0.466 a$ \\
\hline & $\mathrm{FE}$ & $34.57 \pm 0.06$ & $43.13 \pm 0.10$ & $4.21 \pm 0.03$ & $18.10 \pm 0.05$ & $1.25 \mathrm{a}$ & $0.122 \mathrm{a}$ & $0.524 \mathrm{c}$ & $0.420 \mathrm{c}$ & $0.164 \mathrm{c}$ \\
\hline & ME & $35.97 \pm 0.13$ & $40.27 \pm 0.26$ & $3.79 \pm 0.09$ & $19.96 \pm 0.19$ & $1.12 \mathrm{a}$ & $0.105 b$ & $0.555 b$ & $0.496 \mathrm{~b}$ & $0.307 \mathrm{~b}$ \\
\hline \multirow[t]{3}{*}{$\mathrm{Lu}$} & $\mathrm{AE}$ & $37.74 \pm 0.06$ & $38.21 \pm 0.21$ & $2.67 \pm 0.19$ & $21.37 \pm 0.30$ & $1.01 \mathrm{a}$ & $0.071 \mathrm{a}$ & $0.566 \mathrm{a}$ & $0.559 \mathrm{a}$ & $0.333 \mathrm{a}$ \\
\hline & $\mathrm{FE}$ & $39.55 \pm 0.68$ & $37.23 \pm 0.92$ & $2.92 \pm 0.07$ & $20.30 \pm 0.61$ & $0.94 \mathrm{ab}$ & $0.074 \mathrm{a}$ & $0.513 \mathrm{c}$ & $0.545 \mathrm{ab}$ & $0.307 \mathrm{~b}$ \\
\hline & ME & $37.71 \pm 0.64$ & $38.73 \pm 0.19$ & $2.90 \pm 0.05$ & $20.66 \pm 0.85$ & $1.03 \mathrm{a}$ & $0.077 \mathrm{a}$ & $0.548 b$ & $0.533 b$ & $0.300 \mathrm{~b}$ \\
\hline \multirow[t]{3}{*}{ Pl } & $\mathrm{AE}$ & $33.81 \pm 0.27$ & $43.81 \pm 0.69$ & $2.76 \pm 0.08$ & $19.62 \pm 0.33$ & $1.30 \mathrm{a}$ & $0.082 \mathrm{a}$ & $0.580 \mathrm{~b}$ & $0.448 \mathrm{c}$ & $0.110 \mathrm{c}$ \\
\hline & FE & $33.38 \pm 0.43$ & $43.65 \pm 0.35$ & $2.55 \pm 0.13$ & $20.42 \pm 0.56$ & $1.31 \mathrm{a}$ & $0.076 \mathrm{~b}$ & $0.612 \mathrm{a}$ & $0.468 b$ & $0.145 b$ \\
\hline & ME & $34.31 \pm 0.25$ & $41.59 \pm 0.43$ & $2.93 \pm 0.08$ & $21.17 \pm 0.12$ & $1.21 \mathrm{ab}$ & $0.085 \mathrm{a}$ & $0.617 \mathrm{a}$ & $0.509 a$ & $0.278 \mathrm{a}$ \\
\hline \multirow[t]{3}{*}{$\mathrm{Ca}$} & $\mathrm{AE}$ & $34.09 \pm 0.75$ & $43.63 \pm 0.75$ & $3.77 \pm 0.14$ & $18.52 \pm 0.21$ & $1.28 \mathrm{a}$ & $0.111 \mathrm{a}$ & $0.543 \mathrm{ab}$ & $0.424 \mathrm{c}$ & $0.138 \mathrm{c}$ \\
\hline & $\mathrm{FE}$ & $35.40 \pm 0.51$ & $41.77 \pm 0.12$ & $3.26 \pm 0.12$ & $19.59 \pm 0.24$ & $1.18 \mathrm{ab}$ & $0.092 b$ & $0.554 \mathrm{a}$ & $0.469 b$ & $0.203 b$ \\
\hline & ME & $36.60 \pm 0.78$ & $40.2 \pm 0.72$ & $3.15 \pm 0.05$ & $20.10 \pm 0.85$ & $1.10 \mathrm{~b}$ & $0.086 \mathrm{~b}$ & $0.551 \mathrm{a}$ & $0.502 \mathrm{a}$ & $0.262 \mathrm{a}$ \\
\hline
\end{tabular}

${ }^{1}$ Ch Chernozem, Lu Luvisol, Pl Planosol, Ca Cambisol, AE agricultural ecosystem, FE forest ecosystem, ME meadow ecosystem

${ }^{2}$ Values followed by a lowercase letter are not significantly different at $5 \%$

${ }^{3}$ Standard deviation $(\mathrm{n}=3)$

${ }^{4} \omega$ - internal oxidation degree 
Of the HAs of Luvisol the highest content of $\mathrm{C}$ and the lowest of $\mathrm{H}$ were noted for the HAs of the forest soil, whereas the HAs of the arable soil showed the highest value of $\omega$ and the $\mathrm{O} / \mathrm{C}$ ratio. The HAs quality parameters in meadow soil, in general, did not demonstrate any significant differences, as compared with the molecules of the HAs of forest ecosystems.

Of the HAs of Planosol, the highest content of $\mathrm{C}$ and the lowest content of $\mathrm{H}$ and, as a consequence, the lowest value of the $\mathrm{H} / \mathrm{C}$ ratio and the highest values of $\mathrm{O} / \mathrm{H}$ and $\omega$ were recorded for the HAs of meadow soil. The HAs of the agriecosystem showed the lowest value of the $\mathrm{O} / \mathrm{C}$ ratio.

As for the HAs of Cambisol, the lowest content of $\mathrm{C}$ and $\mathrm{O}$ and the highest content of $\mathrm{H}$ and the highest value of the $\mathrm{H} / \mathrm{C}$ ratio and the lowest values of the $\mathrm{O} / \mathrm{H}$ ratio and $\omega$ were noted for the HAs of the arable soil. Interestingly, the significant differences were reported in the value of the $\mathrm{O} / \mathrm{H}$ ratio and parameter $\omega$ between the HAs of the soils of all the ecosystems investigated.

The impact of the land use on the properties of HAs is confirmed by the diagram of the relationships between the values of the $\mathrm{H} / \mathrm{C}$ atomic ratio and parameter $\omega$ (Fig. 2). The molecules of the HAs of meadow soils showed similar values irrespective of the soil type. As for the HAs of the other ecosystems, that soil type was an additional factor determining their properties (e.g. HAs of Luvisol). Generally, the HAs of Luvisol showed the highest contents of $\mathrm{C}$ and lower contents of $\mathrm{H}$, as compared with the HAs of the other soils (Table 3). The highest $\mathrm{C}$ content in the HAs of Luvisol of the forest ecosystem resulted in a low content of the $\mathrm{H} / \mathrm{C}$ ratio and a high value of $\omega$, as compared with the HAs of the forest ecosystem, of the other soil types.

The existing research results have indicated some dependencies between the values of absorbance at the wavelength of 280, 465, and $665 \mathrm{~nm}$ and the structure of HAs. The lowest values of absorbance coefficients were found for the HAs of Luvisol irrespective of the land use and for the molecules of the HAs of Chernozem sampled from the agri-ecosystem

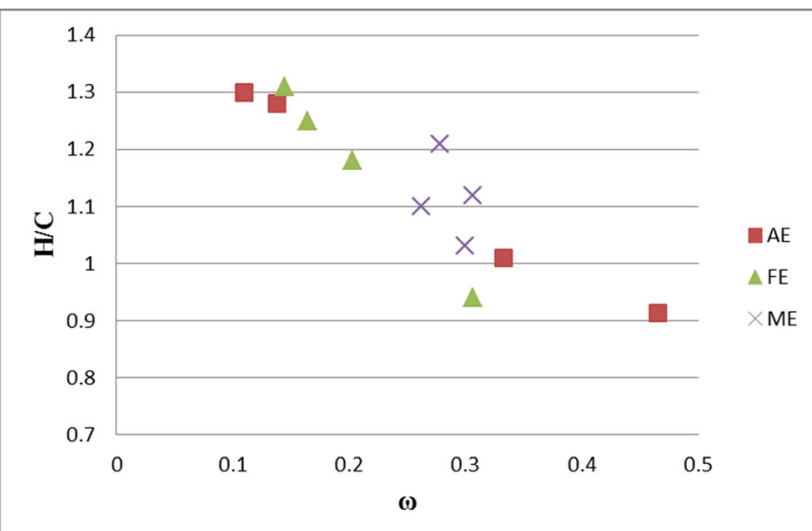

Fig. 2 Relationship between the $\mathrm{H} / \mathrm{C}$ atomic ratio values and parameter $\omega$, where $\mathrm{H}, \mathrm{C}-$ content in atomic $\%, \omega$-internal oxidation degree, $\mathrm{AE}-$ agri-ecosystem, $\mathrm{FE}$ - forest ecosystem, $\mathrm{ME}$ - meadow ecosystem
(Table 4). As reported by, e.g., Kumada (1987), Howard et al. (1998), Tinoco et al. (2015), and Filcheva et al. (2018), lower values of absorbance and higher values of the following coefficients, $\mathrm{A}_{2 / 4}, \mathrm{~A}_{2 / 6}, \mathrm{~A}_{4 / 6}$, and $\Delta \log \mathrm{K}$, point to a chemical "young age" of HAs. Young humic acids show a lower degree of condensation of aromatic structures and a lower molecular weight, as compared with the HAs with a high degree of humification. As results from the data presented in Table 4, the HAs differed in the degree of maturity. Of all the HAs of Luvisol, higher values of the coefficients of absorbance were recorded for the HAs of meadow soil, as compared with the HAs of forest soil and under agricultural use. Similarly, for the HAs of meadow soil of Planosol, there were found higher values of $\mathrm{A}_{2 / 6}$ and $\Delta \log \mathrm{K}$, as compared with the HAs of the agri-ecosystems. However, the HAs of Cambisol under meadow ecosystem use showed, in general, lower values of the coefficients of absorbance as compared with the HAs of the other variants. The values of the coefficients of absorbance recorded for the HAs of Cambisols confirm the dependencies reported by Jonczak (2013), who for the HAs of soils under different land uses (forest, meadow, arable field, fallow, postarable afforestation) noted a higher maturity of humus in stands with grass vegetation (meadow, fallow, afforestation with birch with dense grass cover in forest floor) in relation to other stands. Watanabe et al. (2001) have demonstrated that the relationship between the land use and the degree of HAs humification differed depending on the soil sampling site. On the one hand, the degree of humification of HAs in the topsoil was greatest under secondary forest and least under coffee plantation, whereas for the soil sampled from another site, the degree of humification of HAs was greater under agriculture than under forests. According to the authors, the increase in the degree of humification with decreasing amount of HAs due to changing land use suggests selective decomposition of the molecules or moieties of humic acids with low degrees of humification.

HAs are built from structures with both hydrophobic and hydrophilic properties. By applying the HPLC method, one can divide the molecules of HAs into fractions which are HIL and HOB in nature (Fig. 3). The fractions of the retention time of 4.0-7.0 min show greater HIL properties, whereas the fractions of the retention time between 14.0 and $25.0 \mathrm{~min}$ become more and more HOB (Woelki et al. 1997; Preuße et al. 2000; Debska et al. 2007, 2010, 2012). The share of HIL fractions in the HAs molecules of the soil analysed was lower than the share of HOB fractions, and it ranged from $15.90(\mathrm{Lu} \mathrm{FE})$ to $29.46 \%$ (Ch FE) (Table 5). With the patterns of chromatograms for the HOB fractions, for most HAs, there were separated 3 smaller fractions: HOB-1, HOB-2, and HOB-3 (Fig. $3)$. Irrespective of the factors discussed (land use, soil type), of those hydrophobic fractions, in general, the HAs recorded the highest share of the HOB-2 fraction. It should be noted that the biggest differences between the shares of fractions HOB- 
Table 4 Mean absorbance values with standard deviation and coefficients of absorbance of humic acids

\begin{tabular}{lcccccccccc}
\hline Soils & Ecosystems & $280 \mathrm{~nm}$ & $400 \mathrm{~nm}$ & $465 \mathrm{~nm}$ & $600 \mathrm{~nm}$ & $665 \mathrm{~nm}$ & $\mathrm{~A}_{2 / 4}$ & $\mathrm{~A}_{2 / 6}$ & $\mathrm{~A}_{4 / 6}$ & $\Delta \operatorname{logK} \mathrm{K}^{4}$ \\
\hline $\mathrm{Ch}^{1}$ & $\mathrm{AE}$ & $3.94 \pm 0.12^{3}$ & $2.24 \pm 0.17$ & $1.32 \pm 0.03$ & $0.551 \pm 0.034$ & $0.300 \pm 0.014$ & $2.98 \mathrm{~b}^{2}$ & $13.1 \mathrm{~b}$ & $4.40 \mathrm{~b}$ & $0.609 \mathrm{~b}$ \\
& $\mathrm{FE}$ & $2.73 \pm 0.2$ & $1.04 \pm 0.06$ & $0.571 \pm 0.026$ & $0.156 \pm 0.005$ & $0.084 \pm 0.003$ & $4.78 \mathrm{a}$ & $32.5 \mathrm{a}$ & $6.80 \mathrm{a}$ & $0.824 \mathrm{a}$ \\
& $\mathrm{ME}$ & $3.70 \pm 0.06$ & $1.43 \pm 0.11$ & $0.740 \pm 0.046$ & $0.211 \pm 0.014$ & $0.112 \pm 0.006$ & $5.00 \mathrm{a}$ & $33.0 \mathrm{a}$ & $6.61 \mathrm{a}$ & $0.831 \mathrm{a}$ \\
$\mathrm{Lu}$ & $\mathrm{AE}$ & $4.39 \pm 0.30$ & $2.03 \pm 0.15$ & $1.26 \pm 0.05$ & $0.490 \pm 0.046$ & $0.276 \pm 0.013$ & $3.48 \mathrm{~b}$ & $15.9 \mathrm{~b}$ & $4.57 \mathrm{~b}$ & $0.617 \mathrm{~b}$ \\
& $\mathrm{FE}$ & $4.50 \pm 0.09$ & $2.04 \pm 0.14$ & $1.20 \pm 0.09$ & $0.497 \pm 0.024$ & $0.276 \pm 0.016$ & $3.75 \mathrm{~b}$ & $16.3 \mathrm{~b}$ & $4.35 \mathrm{~b}$ & $0.613 \mathrm{~b}$ \\
& $\mathrm{ME}$ & $3.90 \pm 0.13$ & $1.61 \pm 0.13$ & $0.960 \pm 0.061$ & $0.350 \pm 0.022$ & $0.191 \pm 0.007$ & $4.06 \mathrm{a}$ & $20.4 \mathrm{a}$ & $5.03 \mathrm{a}$ & $0.663 \mathrm{a}$ \\
$\mathrm{Pl}$ & $\mathrm{AE}$ & $3.25 \pm 0.14$ & $1.11 \pm 0.07$ & $0.616 \pm 0.008$ & $0.199 \pm 0.014$ & $0.097 \pm 0.003$ & $5.28 \mathrm{a}$ & $33.5 \mathrm{~b}$ & $6.35 \mathrm{a}$ & $0.746 \mathrm{c}$ \\
& $\mathrm{FE}$ & $3.15 \pm 0.06$ & $1.03 \pm 0.07$ & $0.564 \pm 0.018$ & $0.178 \pm 0.008$ & $0.085 \pm 0.006$ & $5.59 \mathrm{a}$ & $37.1 \mathrm{a}$ & $6.64 \mathrm{a}$ & $0.762 \mathrm{~b}$ \\
& $\mathrm{ME}$ & $3.15 \pm 0.04$ & $1.10 \pm 0.06$ & $0.582 \pm 0.016$ & $0.178 \pm 0.002$ & $0.085 \pm 0.002$ & $5.41 \mathrm{a}$ & $37.1 \mathrm{a}$ & $6.85 \mathrm{a}$ & $0.791 \mathrm{a}$ \\
$\mathrm{Ca}$ & $\mathrm{AE}$ & $2.77 \pm 0.15$ & $0.97 \pm 0.07$ & $0.443 \pm 0.046$ & $0.134 \pm 0.009$ & $0.064 \pm 0.004$ & $6.25 \mathrm{a}$ & $43.3 \mathrm{a}$ & $6.92 \mathrm{a}$ & $0.860 \mathrm{a}$ \\
& $\mathrm{FE}$ & $3.23 \pm 0.07$ & $1.12 \pm 0.11$ & $0.591 \pm 0.012$ & $0.172 \pm 0.007$ & $0.084 \pm 0.003$ & $5.47 \mathrm{~b}$ & $38.5 \mathrm{~b}$ & $7.04 \mathrm{a}$ & $0.814 \mathrm{~b}$ \\
& $\mathrm{ME}$ & $3.68 \pm 0.07$ & $1.31 \pm 0.04$ & $0.700 \pm 0.046$ & $0.221 \pm 0.023$ & $0.111 \pm 0.004$ & $5.26 \mathrm{~b}$ & $33.2 \mathrm{c}$ & $6.31 \mathrm{~b}$ & $0.773 \mathrm{c}$ \\
\hline
\end{tabular}

${ }^{1}$ Ch Chernozem, Lu Luvisol, Pl Planosol, Ca Cambisol, AE agricultural ecosystem, FE forest ecosystem, ME meadow ecosystem

${ }^{2}$ Values followed by a lowercase letter are not significantly different at $5 \%$

${ }^{3}$ Standard deviation $(\mathrm{n}=3)$

${ }^{4} \Delta \log \mathrm{K}=\log \mathrm{A}_{400}-\log \mathrm{A}_{600}$

1, HOB-2, and HOB-3 (Table 5) were identified in the molecules of the HAs of the meadow ecosystem (6.22-8.94 pp). The highest share of the $\Sigma$ HOB fraction was recorded for the HAs of the forest and agri-ecosystem of Luvisol and the lowest for the HAs of the forest and meadow ecosystem of Chernozem. Of the Chernozem HAs, the highest share of $\Sigma \mathrm{HOB}$ was recorded for the HAs of the agri-ecosystem and of the Planosol HAs and the Cambisol HAs in the meadow

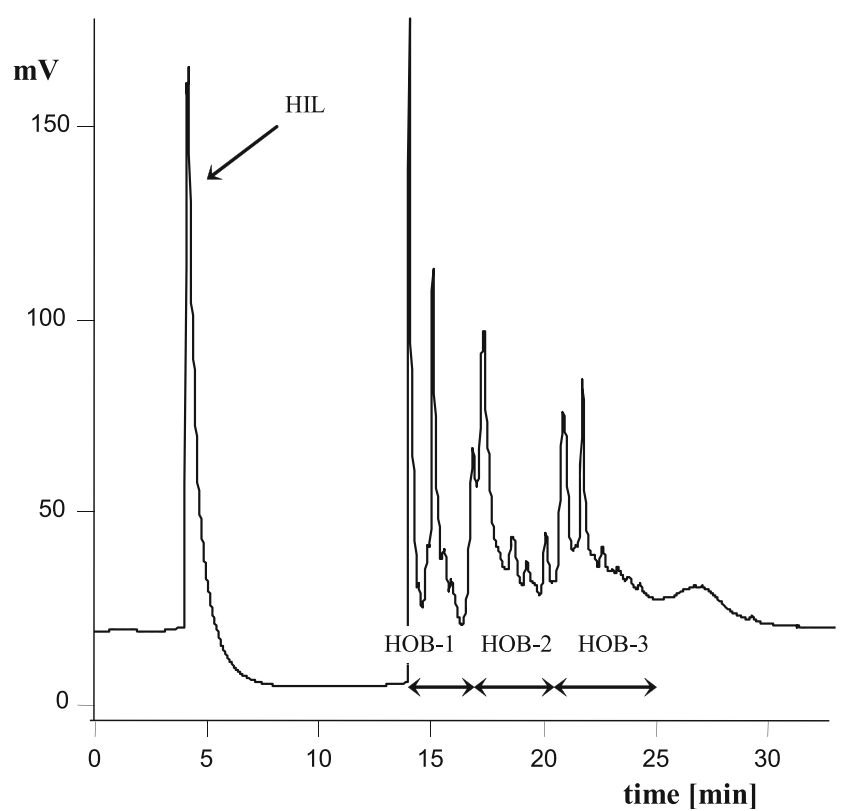

Fig. 3 Selected RP-HPLC chromatogram of humic acids of Chernozem under agricultural use ecosystem. The results point to a strong effect of the soil type on the $\Sigma$ HOB properties of HAs. The changes in the share of the respective fractions resulted in changes in the value of the HIL/ $\Sigma$ HOB ratio. The HAs isolated from the Luvisol, except for ME, showed the lowest and the HAs extracted from the Chernozem, except for AE, the highest values of the HIL/ $\Sigma$ HOB ratio. The values of the HIL/ $\Sigma$ HOB ratio were similar for the HAs of Cambisol of the agri- and forest ecosystem and for the HAs of Chernozem of the forest and meadow ecosystem. For the HAs of Chernozem, no significant differences were found between the values of $\mathrm{HIL} / \mathrm{LHOB}$ in the forest and meadow ecosystem and as for the HAs of Planosol between the agri- and meadow ecosystem. The share of HIL and $\mathrm{HOB}$ fractions and parameter $\mathrm{HIL} / \Sigma \mathrm{HOB}$ is connected with the degree of OM humification. The values of HIL/ $/ \mathrm{HOB}$ of the parameter increase with an increase in the degree of maturity of HAs molecules (Woelki et al. 1997; Preuße et al. 2000; Debska et al. 2007, 2010, 2012). It should also be emphasized that the proportions of both fractions determine the solubility of HAs and, as a result, their migration deep down the soil profile (Woelki et al. 1997; Debska et al. 2007).

Figure 4 provides sample FTIR spectra of the HAs. All the spectra were identified with a presence of the same absorption bands the ranges of which are presented in Table 6. As a result of a detailed spectral analysis, it was found that the intensity of the absorption bands in the molecules of HAs depended on the land use. The HAs of Chernozem and Luvisol under agricultural use showed a higher band intensity in the range of 1730$1710 \mathrm{~cm}^{-1}$, as compared with the molecules of the HAs of the forest and meadow ecosystem. The intensity of the 
Table 5 Mean share of hydrophilic and hydrophobic fractions with standard deviation, total share of hydrophobic fractions $(\Sigma \mathrm{HOB})$, and values of $\mathrm{HIL} / \Sigma \mathrm{HOB}$ ratio of humic acids

\begin{tabular}{|c|c|c|c|c|c|c|c|}
\hline Soils & Ecosystems & $\mathrm{HIL}^{4}$ & HOB-1 & HOB-2 & HOB-3 & $\sum \mathrm{HOB}$ & $\begin{array}{l}\mathrm{HIL} / \\
\sum \mathrm{HOB}\end{array}$ \\
\hline \multirow[t]{3}{*}{$\mathrm{Ch}^{1}$} & $\mathrm{AE}$ & $19.74 \pm 0.44^{3}$ & $24.26 \pm 0.64$ & $28.17 \pm 0.16$ & $27.83 \pm 0.25$ & $80.26 a^{2}$ & $0.246 b$ \\
\hline & $\mathrm{FE}$ & $29.46 \pm 2.23$ & $70.54 \pm 2.15$ & nd & nd & $70.54 b$ & $0.418 \mathrm{a}$ \\
\hline & ME & $29.19 \pm 1.75$ & $27.24 \pm 0.77$ & $24.77 \pm 1.00$ & $18.80 \pm 0.57$ & $70.81 \mathrm{~b}$ & $0.412 \mathrm{a}$ \\
\hline \multirow[t]{3}{*}{$\mathrm{Lu}$} & $\mathrm{AE}$ & $17.75 \pm 1.25$ & $26.28 \pm 1.31$ & $30.59 \pm 1.51$ & $25.37 \pm 1.48$ & $82.25 \mathrm{a}$ & $0.216 b$ \\
\hline & $\mathrm{FE}$ & $15.90 \pm 0.79$ & $26.17 \pm 1.01$ & $31.44 \pm 1.73$ & $26.49 \pm 1.11$ & $84.10 \mathrm{a}$ & $0.189 \mathrm{c}$ \\
\hline & $\mathrm{ME}$ & $25.46 \pm 1.27$ & $21.08 \pm 1.37$ & $27.30 \pm 1.31$ & $26.16 \pm 1.01$ & $74.54 b$ & $0.341 \mathrm{a}$ \\
\hline \multirow[t]{3}{*}{ Pl } & $\mathrm{AE}$ & $23.61 \pm 1.20$ & $24.18 \pm 1.17$ & $28.63 \pm 1.27$ & $23.57 \pm 1.28$ & $76.39 a$ & $0.309 \mathrm{~b}$ \\
\hline & $\mathrm{FE}$ & $27.53 \pm 1.56$ & $21.01 \pm 1.60$ & $26.02 \pm 1.41$ & $25.44 \pm 1.15$ & $72.47 \mathrm{~b}$ & $0.380 \mathrm{a}$ \\
\hline & $\mathrm{ME}$ & $22.90 \pm 1.22$ & $25.43 \pm 1.67$ & $29.66 \pm 1.16$ & $22.01 \pm 0.72$ & $77.10 \mathrm{a}$ & $0.297 b$ \\
\hline \multirow[t]{3}{*}{$\mathrm{Ca}$} & $\mathrm{AE}$ & $25.67 \pm 1.33$ & $74.33 \pm .133$ & nd & nd & $74.33 b$ & $0.345 \mathrm{a}$ \\
\hline & $\mathrm{FE}$ & $25.19 \pm 1.19$ & $24.65 \pm 1.43$ & $28.36 \pm 1.21$ & $21.80 \pm 1.22$ & $74.81 \mathrm{~b}$ & $0.337 \mathrm{a}$ \\
\hline & ME & $22.17 \pm 1.4$ & $25.83 \pm 1.71$ & $30.47 \pm 1.16$ & $21.53 \pm 0.93$ & $77.83 \mathrm{a}$ & $0.285 \mathrm{~b}$ \\
\hline
\end{tabular}

${ }^{1}$ Ch Chernozem, Lu Luvisol, Pl Planosol, Ca Cambisol, AE agricultural ecosystem, FE forest ecosystem, ME meadow ecosystem

${ }^{2}$ Values followed by a lower-case letter are not significantly different at $5 \%$

${ }^{3}$ Standard deviation $(\mathrm{n}=3)$

${ }^{4} H I L$ the share of hydrophilic fraction, $H O B$ the share of hydrophobic fraction $n d$ non-detectable (below detection limit) bands in the range of $3400-3100 \mathrm{~cm}^{-1}$ and $2960-2920$ $\mathrm{cm}^{-1}$ was highest for the HAs of the forest soils. The HAs of Luvisol, Planosol, and Cambisol of the forest ecosystem demonstrated the lowest intensity of the bands in the range of 1500 to $1000 \mathrm{~cm}^{-1}$. As for the HAs of Chernozem, the lowest band intensity for the range from 1660 to $1000 \mathrm{~cm}^{-1}$ was recorded for the soils under agricultural use.

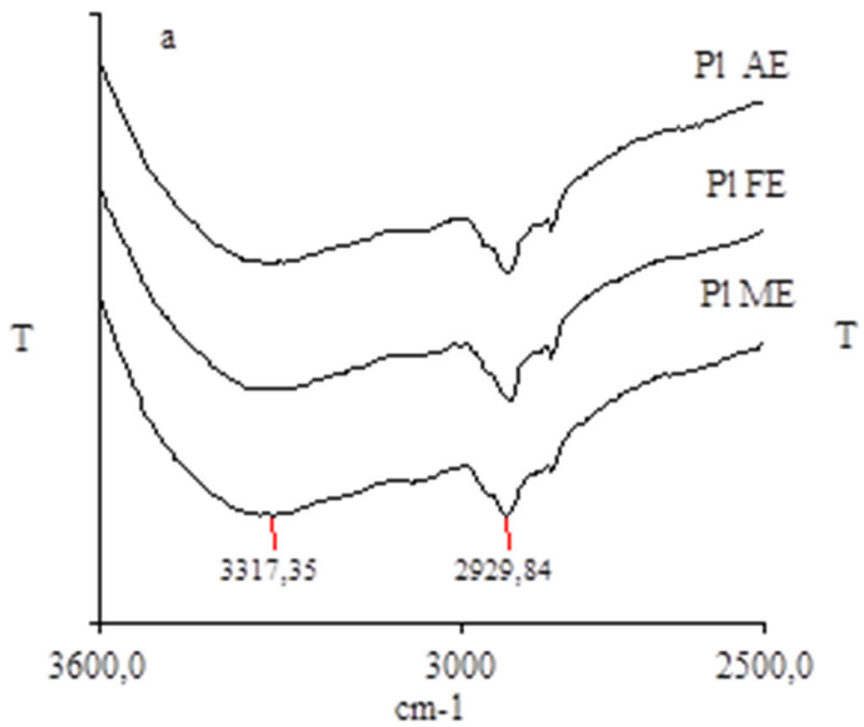

Fig. 4 FT-IR spectra of humic acids of Planosol (Pl) showing the dependence of transmittance $(\mathrm{T})$ on the wavenumber; $\mathbf{a}$ in the range from 3600 to $2500 \mathrm{~cm}^{-1}$, b in the range from 1800 to $1000 \mathrm{~cm}^{-1}$ (AE -
To acquire complete information on the differences (similarities) in the chemical composition of HAs, depending on the soil type and the land use, the cluster analysis was applied based on the elemental composition, spectrometric parameters, as well as the HIL-HOB properties dividing the HAs into two groups (Fig. 5). In the first one, two subgroups were identified. The first subgroup included mostly the HAs of the meadow ecosystem of the following soil types:

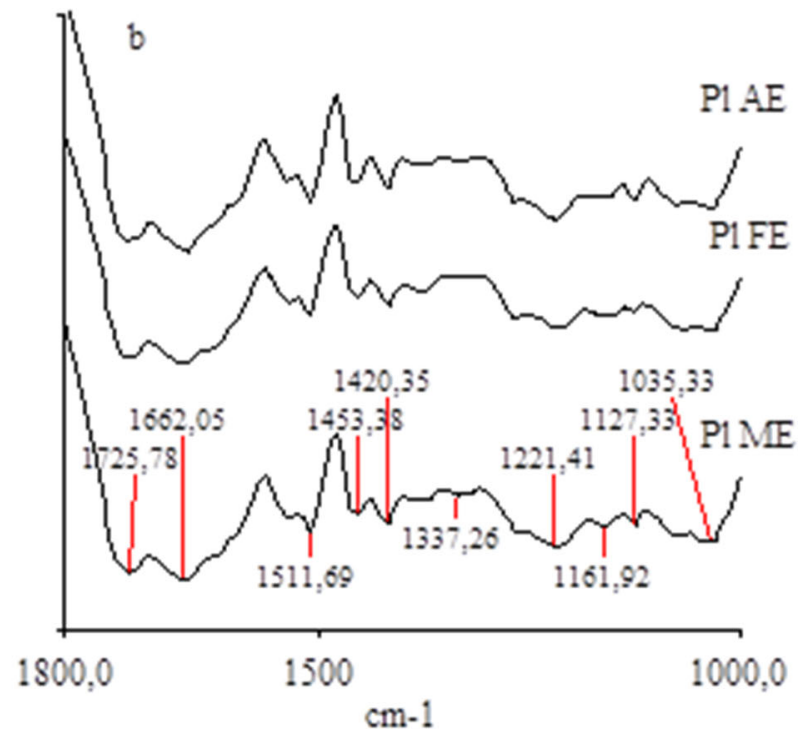

agri-ecosystem, FE - forest ecosystem, ME - meadow ecosystem). Assignment of peaks (bands), see Table 5 
Table 6 List of peaks (bands) present in FT-IR spectra

\begin{tabular}{ll}
\hline Wavenumber $\left(\mathrm{cm}^{-1}\right)$ & Assignment $^{1}$ \\
\hline $3400-3100$ & O-H stretching of alcohols, phenols and acids, N-H stretching \\
$3100-3000$ & C-H groups of aromatic and alicyclic compounds \\
$2960-2920 ; 2850$ & asymmetric and symmetric $\mathrm{C}-\mathrm{H}$ stretching of $\mathrm{CH}_{3}$ and $\mathrm{CH}_{2}$ group \\
$1730-1710$ & $\mathrm{C}=\mathrm{O}$ stretching of carboxyl, aldehyde, ketone group \\
$1660-1620$ & $\mathrm{C}=\mathrm{O}$ of stretching of amide groups; $\mathrm{N}-\mathrm{H}$ deformation \\
$1610-1600$ & $\mathrm{C}-\mathrm{C}$ stretching of aromatic rings \\
$1550-1530$ & $\mathrm{~N}-\mathrm{H}$ deformation, $\mathrm{C}=\mathrm{N}$ stretching (amide II bands) \\
$1520-1500$ & $\mathrm{C}-\mathrm{C}$ stretching of aromatic rings \\
$1460-1440$ & $\mathrm{C}-\mathrm{H}$ asymmetric of $\mathrm{CH}$ and $\mathrm{CH}$ \\
$1420-1400$ & $\mathrm{C}-\mathrm{O}$ stretching and $\mathrm{OH}$ deformation of phenols \\
$1380-1320$ & $\mathrm{C}-\mathrm{N}$ aromatic amine, $\mathrm{COO}-, \mathrm{C}-\mathrm{H}$ stretching \\
$1280-1200$ & $\mathrm{C}-\mathrm{O}$ stretching of aryl ethers, esters and phenols \\
$1160-1030$ & $\mathrm{C}-\mathrm{O}$ stretching alcohols, ethers and polysaccharides \\
\hline
\end{tabular}

${ }^{1}$ Enev et al. 2014; Zhang et al. 2017; Hayes and Swift 2018
Planosol and Cambisol as well as the HAs of the forest ecosystem of Cambisol and HAs Planosol under agricultural use. In the second subgroup, the most similar properties were found for the molecules of the HAs of Chernozem in the forest and meadow ecosystem. In the second group, similar properties were noted for the HAs isolated from Luvisol, irrespective of the ecosystem, and the HAs extracted from Chernozem sampled from the agri-ecosystem. As seen from the diagram, both the soil type and the land use are the factor which determines the properties of HAs. With some approximation, one can assume that Luvisol is the type of the soil which is modified even least considerably by the land use.

To verify the hypothesis formulated in the Introduction, Table 7 presents the correlation coefficients (significant for $p \leq 0.05$ ) between the particle size

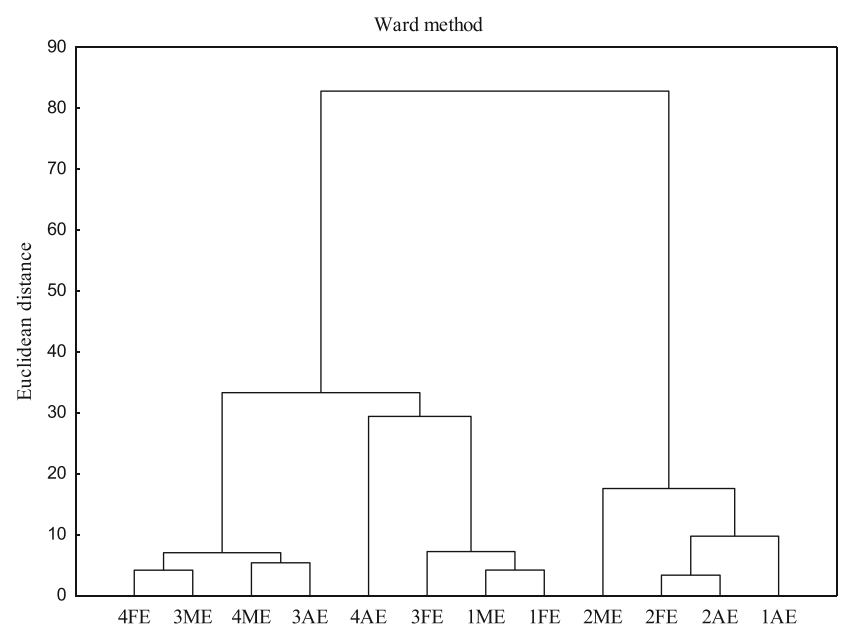

Fig. 5 Cluster analysis determined based on humic acid parameters (1 Chernozem, 2 - Luvisol, 3 - Planosol, 4 - Cambisol, AE - agriecosystem, FE - forest ecosystem, ME - meadow ecosystem) distribution and the properties of HAs. The HAs with a higher "degree of maturity" (a negative significant correlation between the clay content and content of $\mathrm{H}$ in HAs, the values of $\mathrm{H} / \mathrm{C}, \mathrm{A}_{2 / 4}, \mathrm{~A}_{2 / 6}, \mathrm{~A}_{4 / 6}$ and positive between the content of $\mathrm{C}$ and parameter $\omega$ and the values of absorbance) are characteristic for the soils with a higher clay fraction content and a lower sand fraction content. Even earlier Jindaluang et al. (2013) noted the effect of the particle size composition, especially the content of the clay fraction, on the content and the properties of SOM. As seen from the research, the particle size distribution, especially the content of the clay fraction, is the factor affecting also the properties of HAs, mainly their elemental composition and spectrometric properties in the UVVIS range.

\section{Conclusions}

From $\mathrm{H} / \mathrm{C}, \mathrm{O} / \mathrm{C}, \mathrm{O} / \mathrm{H}$, and $\omega$ parameters and absorbance coefficients and the FT-IR spectra, it has been found that the HAs of Chernozem and Luvisol in the agri-ecosystem show a higher "degree of maturity", as compared with the HAs of the meadow and forest ecosystem. However, for the HAs of Cambisol, a higher "degree of maturity" was demonstrated for the meadow ecosystem, as compared with the HAs of the agriand forest ecosystem.

The research results have demonstrated unambiguously that the properties of HAs can be modified by the land use and the scope and that the direction of changes depends on the soil type. The research has identified that the content of clay affects the properties of HAs. Soils with a higher content of clay fraction include HAs with a higher "degree of maturity". It is seen from the positive (significant) values of 
Table 7 Correlations between the particle size distribution content (\%) and basic parameters of humic acids

\begin{tabular}{|c|c|c|c|c|c|c|c|c|c|}
\hline & $\mathrm{C}$ & $\mathrm{H}$ & $\mathrm{H} / \mathrm{C}$ & $\omega$ & $\mathrm{A}_{280}$ & $\mathrm{~A}_{665}$ & $\mathrm{~A}_{2 / 4}$ & $\mathrm{~A}_{2 / 6}$ & $\mathrm{~A}_{4 / 6}$ \\
\hline Clay & $0.790^{*}$ & $-0.728^{*}$ & $-0.745^{*}$ & $0.642^{*}$ & $0.597^{*}$ & $0.620^{*}$ & $-0.733^{*}$ & $-0.719^{*}$ & $-0.631^{*}$ \\
\hline Silt & $0.579^{*}$ & -0.469 & $-0.538^{*}$ & 0.321 & 0.498 & 0.406 & -0.305 & -0.335 & -0.378 \\
\hline Sand & $-0.760^{*}$ & $0.597^{*}$ & $0.667^{*}$ & -0.448 & $-0.585^{*}$ & -0.514 & 0.481 & 0.481 & 0.493 \\
\hline
\end{tabular}

${ }^{*}$ Significant correlations for $\mathrm{p} \leq 0.05$

the coefficient of correlation between the clay fraction content and the content of $\mathrm{C}$ in the molecules of HAs, the values of the degree of internal oxidation and absorbance values, and the negative (significant) correlations between the content of the clay fraction and the content of $\mathrm{H}$ and the values of the $\mathrm{H} / \mathrm{C}, \mathrm{A}_{2 / 4}, \mathrm{~A}_{2 / 6}$, and $\mathrm{A}_{4 / 6}$ ratios.

Supplementary Information The online version contains supplementary material available at https://doi.org/10.1007/s11356-021-14616-9.

Acknowledgements We thank the Ministry of Science and Higher Education for their support.

Availability of data and materials Data sharing is not applicable to this article.

Author contribution Conceptualization: Magdalena Banach-Szott, Bozena Debska, and Erika Tobiasova

Methodology: Magdalena Banach-Szott, Bozena Debska, and Erika

Tobiasova

Investigation: Magdalena Banach-Szott and Erika Tobiasova

Data curation - compiled and analysed the results: Magdalena

Banach-Szott and Bozena Debska

Writing - original draft preparation: Magdalena Banach-Szott and Bozena Debska

Writing - review and editing: Magdalena Banach-Szott and Bozena Debska

Funding acquisition: Bozena Debska

All authors have read and agreed to the published version of the manuscript.

Funding The research has been made as part of BS-3/2017 research project, financed by the Ministry of Science and Higher Education.

\section{Declarations}

Ethics approval and consent to participate Not applicable.

Consent for publication The authors confirm that the final version of the manuscript has been reviewed, approved, and agreed for publication by all authors.

Competing interests The authors declare no competing interests.

Open Access This article is licensed under a Creative Commons Attribution 4.0 International License, which permits use, sharing, adaptation, distribution and reproduction in any medium or format, as long as you give appropriate credit to the original author(s) and the source, provide a link to the Creative Commons licence, and indicate if changes were made. The images or other third party material in this article are included in the article's Creative Commons licence, unless indicated otherwise in a credit line to the material. If material is not included in the article's Creative Commons licence and your intended use is not permitted by statutory regulation or exceeds the permitted use, you will need to obtain permission directly from the copyright holder. To view a copy of this licence, visit http://creativecommons.org/licenses/by/4.0/.

\section{References}

Arrouays D, Saby N, Walter C, Lemercier B, Schvartz C (2006) Relationships between particle-size distribution and organic carbon in French arable topsoils. Soil Use Manag 22(1):48-51. https://doi. org/10.1111/j.1475-2743.2006.00020.x

Banach-Szott M, Debska B (2006) Chromatographic separation of humic acids of a forest soil. In: Frimmel FH, Abbt-Braun G (eds) Humic substances - linking structure to functions, Proceedings of the 13th Meeting of the International Humic Substances Society. IHSS, Karlsruhe, pp 225-228

Barancikova G, Makovnikova J, Halas J (2016) Effect of land use change on soil organic carbon. Agriculture 62:10-18. https://doi.org/10. 1515/agri-2016-0002

Boguta P, D'Orazio V, Sokołowska Z, Senesi N (2016) Effects of selected chemical and physicochemical properties of humic acids from peat soils on their interaction mechanisms with copper ions at various pHs. J Geochem Explor 168:119-126. https://doi.org/10.1016/j. gexplo.2016.06.004

Canellas LP, Piccolo A, Dobbss LB, Spaccini R, Olivares FL, Zandonadi DB, Façanha AR (2010) Chemical composition and bioactivity properties of size-fractions separated from a vermicompost humic acid. Chemosphere 78:457-466. https://doi.org/10.1016/j. chemosphere.2009.10.018

Chen J, Gu B, LeBoeuf E, Pan H, Dai S (2002) Spectroscopic characterization of the structural and functional properties of natural organic matter fractions. Chemosphere 48:59-68

Chin YP, Aiken G, O'Loughlin E (1994) Molecular weight, polydispersity, and spectroscopic properties of aquatic humic substances. Environ Sci Technol 28:1853-1858

Cocozza C, Miano T (2002) Structural resolution of metal-humic acids interactions through deconvolution FT-IR spectroscopy. In: Davis G, Ghabbour EA (eds) Proceedings of the $11^{\text {th }}$ IHSS Meeting. IHSS, Boston, pp 264-266

Conant RT, Paustian K, Elliott ET (2001) Grassland management and conversion into grassland: effects on soil carbon. Ecol Appl 11:343-355

De Moraes GM, Da Silva Xavier FAS, Mendonca ES, De Araujo Filho JA, De Oliveira TS (2011) Chemical and structural characterization of soil humic substances under agroforestry and conventional systems. Rev Bras Cienc Solo 35(5):1597-1608. https://doi.org/10. 1590/S0100-06832011000500014

Debska B, Banach-Szott M, Dziamski A, Gonet SS (2010) Chromatographic characteristics (HPLC, HPSEC) of humic acids of soil fertilised with various organic fertilisers. Chem Ecol 26(S2):49-57 
Debska B, Drag M, Banach-Szott M (2007) Molecular size distribution and hydrophilic and hydrophobic properties of humic acids isolated from forest soil. Soil Water Res 2(2):45-53. https://doi.org/10. 17221/2113-SWR

Debska B, Drag M, Tobiasova E (2012) Effect of post-harvest residue of maize, rapeseed, and sunflower on humic acids properties in various soils. Pol J Environ Stud 21(3):603-613

Debska B, Gonet I (2007) Share of hydrophilic and hydrophobic fractions in humic acids formed as a result of post-harvest residue decomposition. Pol J Soil Sci 40(1):57-65

Dergacheva MI, Nekrasova OA, Okoneshnikova MV, Vasileva DI, Gavrilov DA, Ochur KO, Ondar EE (2012) Ratio of elements in humic acids as a source of information on the environment of soil formation. Contemp Probl Ecol 5:497-504. https://doi.org/10.1134/ S1995425512050022

Enev V, Pospisilova L, Klucakova M, Liptaj T, Doskocil L (2014) Spectral characterization of selected humic substances. Soil Water Res 9(1):9-17. https://doi.org/10.17221/39/2013-SWR

Feller C, Beare MH (1997) Physical control of soil organic matter dynamics in the Tropics. Geoderma 79:69-116. https://doi.org/10. 1016/S0016-7061(97)00039-6

Filcheva E, Hristova M, Nikolova P, Popova T, Chakalov K, Savov V (2018) Quantitative and qualitative characterisation of humic products with spectral parameters. J Soils Sediments 18(8):2863-2867. https://doi.org/10.1007/s11368-018-2021-4

Fuentes M, Baigorri R, Gonzalez-Gaitano G, Garcia-Mina JM (2007) The complementary use of 1H NMR, 13C NMR, FTIR and size exclusion chromatography to investigate the principal structural changes associated with composting of organic materials with diverse origin. Org Geochem 38:2012-2023. https://doi.org/10.1016/ j.orggeochem.2007.08.007

Gonet SS, Debska B (1999) Properties of humic acids produced during decomposition of plant residues in soil. Rost Vyroba 45(10):455-460

Gonet SS, Debska B, Zaujec A, Banach-Szott M, Szombathova N (2007) Effect of the tree species and soil-and-climate conditions on the properties of humus in forest soils. In: Gonet SS, Markiewicz M (eds) Role of organic matter in the environment. PTSH, Wroclaw, pp 61-98

Gonzalez-Perez M, Milori DMBP, Colnago LA, Martin-Neto L, Melo WJA (2007) Laser-induced fluorescence spectroscopic study of organic matter in a Brazilian Oxisol under different tillage systems. Geoderma 138:20-24

Guimaraes DV, Isidoria M, Gonzaga S, Da Silva TO, Da Silva TL, Da Silva DN, Silva Matias MI (2013) Soil organic matter pools and carbon fractions in soil under different land uses. Soil Tillage Res 126:177-182. https://doi.org/10.1016/j.still.2012.07.010

Guo L, Gifford R (2002) Soil carbon stocks and land use change: a metaanalysis. Glob Chang Biol 8:345-360. https://doi.org/10.1046/j. 1354-1013.2002.00486.x

Hassink J, Whitmore AP, Kubat J (1997) Size and density fractionation of soil organic matter and the physical capacity of soils to protect organic matter. Eur J Agron 7(1-3):189-199

Hayes MHB, Clapp CE (2001) Humic substances: considerations of compositions, aspects of structure, and environmental influences. Soil Sci 166:723-737

Hayes MHB, Swift RS (2018) An appreciation of the contribution of Frank Stevenson to the advancement of studies of soil organic matter and humic substances. J Soils Sediments 18(4):1212-1231. https://doi.org/10.1007/s11368-016-1636-6

Howard PJA, Howard DM, Lowe LE (1998) Effects of tree species and soil physico-chemical conditions on the nature of soil organic matter. Soil Biol Biochem 30(3):285-297. https://doi.org/10.1016/ S0038-0717(97)00138-7

IUSS, Working Group WRB (2014) World reference base for soil resources 2014, World Soil Resources Reports No. 106. FAO, Rome

Jindaluang W, Kheoruenromne I, Suddhiprakarn A, Singh BP, Singh B (2013) Influence of soil texture and mineralogy on organic matter content and composition in physically separated fractions soil in Thailand. Geoderma 195-196:207-219. https://doi.org/10.1016/j. geoderma.2012.12.003

Jonczak J (2013) Soil organic matter properties in stagnic luvisols under different land use types. Acta Agrophysica 20(4):565-576

Kaiser K, Guggenberger G (2000) The role of DOM sorption to mineral surfaces in the preservation of organic matter in soils. Org Geochem 31(7-8):711-725. https://doi.org/10.1016/S0146-6380(00)00046-2

Kampf I, Holzel N, Storrle M, Broll G, Kiehl K (2016) Potential of temperate agricultural soils for carbon sequestration: A metaanalysis of land-use effects. Sci Total Environ 566-567:428-435. https://doi.org/10.1016/j.scitotenv.2016.05.067

Korec P, Lauko V, Tolmaci L, Zubricky G, Micietova E (1997) Region and districts of Slovakia. A new administrative structure. Bratislava, Slovakia Q111. (in Slovak)

Kukuls I, Klavins M, Nikodemus O, Kasparinskis R, Brumelis (2019) Changes in soil organic matter and soil humic substances following the afforestation of former agricultural lands in the boreal-nemoral ecotone (Latvia). Geoderma Reg 16:e00213. https://doi.org/10. 1016/j.geodrs.2019.e00213

Kumada K (1987) Chemistry of soil organic matter. Elsevier, Amsterdam

Kunlanit B, Butnan S, Vityakon P (2019) Land--use changes influencing c sequestration and quality in topsoil and subsoil. Agronomy 9(9): 520. https://doi.org/10.3390/agronomy 9090520

Lal R (1994) Tillage effects on soil degradation, soil resilience, soil quality, and sustainability. Soil Tillage Res 27:1-8

Lal R (2004) Soil C sequestration to mitigate climate change. Geoderma 123:1-22

Lal R (2006) Soil carbon sequestration in Latin America. In: Lal R, Cerri CC, Bernoux M, Etcheves J, Cerri E (eds) Carbon sequestration in soils of Latin America. Food Products Press, New York, pp 49-64

Lal R (2011) Sequestering carbon in soils of agro-ecosystems. Food Policy 36:533-539

Lanyi K (2010) Assessment of the relations between the spectroscopic characteristics of soils and their ability to adsorb organic pollutants. Microchem J 79:249-256

Leifeld J, Bassin S, Fuhrer J (2005) Carbon stocks in Swiss agricultural soils predicted by land-use, soil characteristics, and altitude. Agric Ecosyst Environ 105(1-2):255-266. https://doi.org/10.1016/j.agee. 2004.03.006

Lettens S, Van Orshovena J, Van Wesemael B, De Vos B, Muys B (2005) Stocks and fluxes of soil organic carbon for landscape units in Belgium derived from heterogeneous data sets for 1990 and 2000. Geoderma 127(1-2):11-23. https://doi.org/10.1016/j.geoderma.2004.11.001

Liang A, Yang X, Zhang X, McLaughlin N, Shen Y, Li W (2009) Soil organic carbon changes in particle-size fractions following cultivation of black soils in China. Soil Tillage Res 105(1):21-26. https:// doi.org/10.1016/j.still.2009.05.002

Mannetje LT (2002) Advances in grassland science. NJAS - Wagen J Life Sc 50(2):195-221

Martin MP, Wattenbach M, Smith P, Meersmans J, Jolivet C, Boulonne L, Arrouays D (2011) Spatial distribution of soil organic carbon stocks in France. Biogeosciences 8(5):1053-1065. https://doi.org/ 10.5194/bg-8-1053-2011

McCarthy P (2001) The principles of humic substances. Soil Sci 166: 738-751

Meersmans J, De Ridder F, Canters F, De Baets S, Van Molle M (2008) A multiple regression approach to assess the spatial distribution of soil organic carbon (SOC) at the regional scale (Flanders, Belgium). Geoderma 143(1-2):1-13. https://doi.org/10.1016/j.geoderma.2007.08.025

Milori DMBP, Martin-Neto L, Bayer C, Mielniczuk J, Bagnato VS (2002) Humification degree of soil humic acids determined by fluorescence spectroscopy. Soil Sci 167:739-749

Minami K, Goudriaan JEA, Lantinga EA, Kimura T (1993) Significance of grasslands in emission and absorption of greenhouse gases In: 
Proceedings of the XVIIth International Grassland Congress 2. pp $1231-1238$

Moran Vieyra FE, Palazzi VI, Sanchez de Pinto MI, Borsarelli CD (2009) Combined UV-Vis absorbance and fluorescence properties of extracted humic substances-like for characterization of composting evolution of domestic solid wastes. Geoderma 151(3-4):61-67

Murty D, Kirschbaum MU, McMurtrie RE, McGilvray H (2002) Does conversion of forest to agricultural land change soil carbon and nitrogen? A review of the literature. Glob Chang Biol 8:105-123. https://doi.org/10.1046/j.1354-1013.2001.00459.x

Orlov DS, Grishina LA (1981) Practical works of the humus chemistry. Moscow State University Publishers, Moscow (In Russian)

Pajaczkowska J, Sulkowska A, Sulkowski WW, Jedrzejczyk M (2003) Spectroscopic study of the humification process during sewage sludge treatment. J Mol Struct 651-653:141-149

Piccolo A (2001) The supramolecular structure of humic substances. Soil Sci 166:810-832

Poeplau C, Don A, Vesterdal L, Leifeld J, Van Wesemael B, Schumacher J, Gensior A (2011) Temporal dynamics of soil organic carbon after land-use change in the temperate zone - carbon response functions as a model approach. Glob Chang Biol 17(7):2415-2427. https:// doi.org/10.1111/j.1365-2486.2011.02408.x

Polak J, Bartoszek M, Zadło M, Kos A, Sulkowski WW (2011) The spectroscopic studies of humic acid extracted from sediment collected at different seasons. Chemosphere 84:1548-1555

Preuße G, Friedrich S, Salzer R (2000) Retention behavior of humic substances in reversed phase HPLC. Fresenius J Anal Chem 368:268-273

Rice J, MacCarthy P (1991) Statistical evaluation of the elemental composition of humic substances. Org Geochem 17:635-648

Rodriguez FJ, Schlenger P, García-Valverde M (2016) Monitoring changes in the structure and properties of humic substances following ozonation using UV-Vis, FTIR and H NMR techniques. Sci Total Environ 541:626-637

Sajgalik J, Cabalova D, Schutznerova V, Samalikova M, Zeman O (1986) Geology. ALFA, SNTL, Bratislava

Sanchez-Monedero MA, Cegarra J, Garcia D, Roig A (2002) Chemical and structural evolution of humic acids during organic waste composting. Biodegradation 13:361-371

Schmidt MWI, Torn MS, Abiven S, Dittmar T, Guggenberger G, Janssens AI, Kleber M, Kogel-Knabner I, Lehmann J, Manning ACD, Nannipieri P, Rasse PD, Weiner S, Trumbore ES (2011) Persistence of soil organic matter as an ecosystem property. Nature 478:49-56

Sierra MD, Giovanela M, Parlanti E, Soriano-Sierra EJ (2006) 3Dfluorescence spectroscopic analysis of HPLC fractionated estuarine fulvic and humic acids. J Braz Chem Soc 17(1):113-124

Six J, Conant RT, Paul EA, Paustian K (2002) Stabilization mechanisms of soil organic matter: implications for C-saturation of soils. Plant Soil 241(2):155-176

Sollins P, Homann P, Caldwell BA (1996) Stabilization and destabilization of soil organic matter: mechanisms and controls. Geoderma 74(1-2):65-105

Spaccini R, Piccolo A, Haberhauer GF, Gerzabek M (2006) Transformation of organic matter from maize residues into labile and humic fractions of three European soils as revealed by $13 \mathrm{C}$ distribution and CPMAS-NMR Spectra. Eur J Soil Sci 51(4):583594. https://doi.org/10.1111/j.1365-2389.2000.00341.x

Tan KH (1998) Principles of soil chemistry. Dekker, New York

Tan KH (2014) Humic matter in soil and the environment: principles and controversies. Dekker, New York

Tinoco P, Almendros G, Gonzalez-Vila FJ, Sanz J, Gonzalez-Perez JA (2015) Revisiting molecular characteristics responsive for the aromaticity of soil humic acids. J Soils Sediments 15:781-791. https:// doi.org/10.1007/s11368-014-1033-y
Trubetskaya OE, Trubetskoj OA, Voyard G, Richard C (2013) Determination of hydrophobicity and optical properties of soil humic acids isolated by different methods. J Geochem Explor 132:84 89. https://doi.org/10.1016/j.gexplo.2013.06.004

Van Krevelen DW (1950) Graphical-statistical method for investigation of the structure of coal. Fuel 26:269-284

Van Reeuwijk LP (2002) Procedures for soil analysis. International Soil Reference and Information Centre, Wageningen

Viscarra-Rossel RA, Webster R, Bui EN, Baldock JA (2014) Baseline map of organic carbon in Australian soil to support national carbon accounting and monitoring under climate change. Glob Chang Biol 20(9):2953-2970. https://doi.org/10.1111/gcb.12569

Von Lutzow M, Kogel-Knabner I, Ekschmitt K, Matzner E, Guggenberger G, Marschner B, Flessa H (2006) Stabilization of organic matter in temperate soils: mechanisms and their relevance under different soil conditions - a review. Eur J Soil Sci 57(4):426445. https://doi.org/10.1111/j.1365-2389.2006.00809.x

Watanabe A, Rumbanraja J, Tsutsuki K, Kimura M (2001) Humus composition of soils under forest, coffee and arable cultivation in hilly areas of south Sumatra, Indonesia. Eur J Soil Sci 52:599-606. https://doi.org/10.1046/j.1365-2389.2001.00410.x

Wei X, Shao M, Gale W, Li L (2014) Global pattern of soil carbon losses due to the conversion of forests to agricultural land. Sci Rep 4:4062. https://doi.org/10.1038/srep04062

Weishaar JL, Aiken GR, Bergamaschi BA, Fram MS, Fujii R, Mopper K (2003) Evaluation of specific ultraviolet absorbance as an indicator of the chemical composition and reactivity of dissolved organic carbon. Environ Sci Technol 37:4702-4708

Wiesmeier M, Munro S, Barthold F, Steffens M, Schad P, KogelKnabner I (2015) Carbon storage capacity of semi-arid grassland soils and sequestration potentials in northern China. Glob Chang Biol 21:3836-3845. https://doi.org/10.1111/gcb.12957

Wiesmeier M, Urbanski L, Hobley E, Lang B, Von Lutzow M, MarinSpiotta E, Van Wesemael B, Rabot E, Lieb M, Garcia-Franco N, Wollschlager U, Vogel HJ, Kogel-Knabner I (2019) Soil organic carbon storage as a key function of soils - a review of drivers and indicators at various scales. Geoderma 333:149-162. https://doi.org/ 10.1016/j.geoderma.2018.07.026

Woelki G, Friedrich S, Hanschmann G, Salzer R (1997) HPLC fractionation and structural dynamics of humic acids. Fresenius J Anal Chem 357(5):548-552

Yamashita Y, Jaffe R, Maie N, Tanoue E (2008) Assessing the dynamics of dissolved organic matter (DOM) in coastal environments by excitation emission matrix fluorescence and parallel factor analysis (EEM-PARAFAC). Limnol Oceanogr 53:1900-1908

Zech W, Senesi N, Guggenberger G, Kaiser K, Lehmann J, Miano TM, Miltner A, Schroth G (1997) Factors controlling humification and mineralization of soil organic matter in the tropics. Geoderma 79:117-161

Zhang J, An T, Chi F, Wei D, Zhou B, Hao X, Jin L, Wang J (2019) Evolution over years of structural characteristics of humic acids in Black Soil as a function of various fertilization treatments. J Soils Sediments 19:1959-1969. https://doi.org/10.1007/s11368-018-2212-z

Zhang J, Wang J, An T, Wei D, Chi F, Zhou B (2017) Effects of long-term fertilization on soil humic acid composition and structure in Black Soil. PLoS One 12(11):1-14. https://doi.org/10.1371/journal.pone.0186918

Zinn YL, Lal R, Bigham JM, Resck DVS (2007) Edaphic controls on soil organic carbon retention in the Brazilian cerrado: texture and mineralogy. Soil Sci Soc Am J 71(4):1204-1214. https://doi.org/10. 2136/sssaj2006.0015

Publisher's note Springer Nature remains neutral with regard to jurisdictional claims in published maps and institutional affiliations. 